\title{
La resonancia magnética en la patología glandular salival del paciente anciano
}

\author{
Paz Expósito J*, Velasco Ortega E**, Martínez-Sahuquillo Márquez A***
}

\section{RESUMEN}

Objetivo. Valorar la utilidad de la Imagen por Resonancia Magnética (RM) en el diagnóstico de la patología de las glándulas salivales en el paciente anciano.

Pacientes y Método. Se presentan 18 pacientes mayores de 65 años con diversas patologías de las glándulas salivales, estudiados por RM, imán superconductivo de 1,5 Tesla, realizándose secuencias Spin Echo ponderada T1 en los planos de incidencia axial y coronal y secuencia Spin Echo T2 en plano axial, con un espesor de corte de $3 \mathrm{~mm}$.

Resultados. La RM muestra, fundamentalmente, imágenes homogéneas de una intensidad de señal baja o intermedia en las secuencias Spin Echo T1 y de intensidad alta en la secuencia Spin Echo T2 en la patología tumoral benigna, e imágenes heterogéneas de una intensidad de señal baja o intermedia en ambas secuencias Spin Echo T1 y T2 en la patología tumoral maligna. La RM permite identificar la lesión glandular salival, sus relaciones intraglandulares (nervio facial, paquete vascular) y extraglandulares (base de cráneo y cuello).

Conclusiones. La RM constituye el método diagnóstico por la imagen de primera elección en el estudio de los procesos patológicos tumorales que afectan a las glándulas salivales en el paciente anciano.

Palabras Clave: anciano, resonancia magnética, glándulas salivales, patología salival, tumor, parótida, submaxilar.

\section{ABSTRACT}

Objective. Assessment to Magnetic Resonance Imaging (MRI) as diagnosis method in salivary glands pathology of aged patients.

Patients and Methods. We present eighteen 65 year and over patients with salivary glands diseases, studied by RMI, with the $1.5 \mathrm{~T}$ system, performed imaging spin echo T1-weighted sequences on coronal and tranverse plans, and spin echo T2-weighted sequences on tranverse plans. The scan thickness was $3 \mathrm{~mm}$.

Results. MRI showed, mainly, homogeneous imaging of low-to-intermediate signal intensity on spin echo T1 and high signal intensity on T2 in tumoral benign pathology and heterogeneous imaging of low-to-intermediate signal intensity on spin echo T1 and T2 in tumoral malign pathology. MRI confirmed the presence of the glands salivary diseases, and permits the evaluation of the relationship of lesions to the facial nerve and vascular complex; and extension on head and neck.

Conclusions. Today MRI is the best imaging diagnosis method in the study of salivary glands tumours in aged patients.

Key words: aged patient, magnetic resonance, salivary glands, salivary deseases, tumour, parotid gland, submandibular gland.

Aceptado para publicación: Octubre 2003.

* J Jefe de Servicio Radiodiagnóstico. Hospital Juan Ramón Jiménez. Huelva.

** Profesor Titular Odontología Integrada de Adultos. Facultad Odontología. Sevilla.

*** Profesor Titular Medicina Bucal. Facultad Odontología. Sevilla.

Paz Expósito J, Velasco Ortega E, Martínez-Sahuquillo Márquez A. La resonancia magnética en la patología glandular salival del paciente anciano. Av. Odontoestomatol 2004; 20-3: 147-155. 


\section{INTRODUCCIÓN}

La patología de las glándulas salivales es relativamente frecuente entre los pacientes adultos de edad avanzada. En este sentido, son diversos los procesos patológicos salivales que pueden afectar al paciente anciano, como son las inflamaciones o sialoadenitis, la litiasis salival, los trastornos inmunitarios como el síndrome de Sjögren, y sobre todo, los tumores benignos y malignos. La mayoría de las lesiones salivales glandulares afectan a la parótida (más del $80 \%$ ). Los tumores salivales malignos presentan una incidencia máxima en la sexta y séptima décadas de la vida (1-2).

El diagnóstico de la patología glandular salival en el paciente anciano comienza con la historia clínica y la exploración física, que demuestran frecuentemente, la existencia de un aumento de tamaño de la glándula salival afectada. La elección de la técnica diagnóstica por la imagen ha evolucionado en los últimos años. Si la historia clínica es de una tumefacción aguda, difusa y dolorosa, se debe sospechar un proceso inflamatorio, recomendándose la utilización de la ecografía y/o Tomografía Computerizada (TC). En contraste, el hallazgo clínico de una masa glandular salival con hipersensibilidad ligera o nula sugiere una lesión tumo- ral, recomendándose la Resonancia Magnética, aunque la TC puede ser una alternativa aceptable (3-4).

Los métodos diagnósticos por la imagen orientan hacia la naturaleza de la lesión glandular salival, que después debe ser confirmada por la histopatología. En este sentido, la RM puede contribuir de forma decisiva a la identificación de las características morfológicas de la diversa patología glandular salival que afectan al paciente anciano, lo que constituye el objetivo del presente estudio.

\section{MATERIAL Y MÉTODO}

103 pacientes con el diagnóstico clínico de patología de las glándulas salivales fueron remitidos a la Unidad de Resonancia Magnética de la Clínica Sagrado Corazón de Sevilla por los Servicios de Cirugía Maxilo-facial y Cirugía Plástica de los Hospitales Universitarios (Virgen del Rocío, Virgen Macarena y Virgen de Valme) del Servicio Andaluz de Sevilla, para su valoración por RM.

18 pacientes mayores de 65 años con sospecha clínica de tumoración de las glándulas salivales fueron

TABLA 1. HALLAZGOS CLÍNICOS E HISTOPATOLÓGICOS

\begin{tabular}{|cccccc|}
\hline Paciente & Edad & Sexo & Diagnóstico & Evolución & Glándula \\
\hline 1 & 69 & Varón & Tumor de Warhin & 2 años & Parótida I \\
2 & 73 & Varón & Recidiva carcinoma mucoepidermoide & 6 meses & Parótida I \\
3 & 78 & Mujer & Recidiva adenoma pleomorfo & 1 año & Parótida D \\
4 & 79 & Varón & Adenoma pleomorfo & 3 años & Parótida D \\
5 & 78 & Mujer & Carcinoma mucoepidermoide & 3 años & Parótida D \\
6 & 65 & Mujer & Síndrome de Sjögren & 2 años & Parótida I \\
7 & 65 & Varón & Lipoma & 3 años & Parótida I \\
8 & 67 & Varón & Carcinoma mucoepidermoide & 3 meses & Parótida D \\
9 & 70 & Mujer & Adenoma pleomorfo & 6 años & Parótida I \\
10 & 67 & Varón & Adenoma pleomorfo & 5 años & Parótida I \\
11 & 70 & Mujer & Submaxilitis & 1 mes & Submaxilar D \\
12 & 71 & Varón & Tumor de Warthin & 1,5 años & Parótida I \\
13 & 67 & Varón & Carcinoma anaplástico & 6 meses & Parótida D \\
14 & 65 & Mujer & Recidiva carcinoma células acinares & 3 meses & Parótida I \\
15 & 70 & Varón & Carcinoma indiferenciado & 7 meses & Parótida D \\
16 & 74 & Varón & Parotiditis aguda & 1 semana & Parótida I \\
17 & 66 & Mujer & Carcinoma epidermoide & 6 meses & Parótida I \\
18 & 70 & Mujer & Adenoma pleomorfo & 2 años & Parótida D \\
\hline
\end{tabular}


valorados por RM. Los pacientes comprendían 10 varones y 8 mujeres (Tabla 1), con una edad media de 70,2 años (rango: 65-79 años).

Los pacientes fueron estudiados con un equipo de RM de General Electric modelo Signa (Milwaukee, EE.UU., 1996) superconductivo de una intensidad de campo de 1,5 Testa. Se practicaron en cada paciente secuencias ponderadas en Spin Echo (SE) T1 con un Tiempo de Repetición (TR) de 840 msg, un Tiempo de Echo (TE) de $15 \mathrm{msg}$, un campo de visión (FOV) de 20 x $20 \mathrm{~cm}$, y una matriz de 512 x 192 en los planos de incidencia axial y coronal, con un espesor de corte de $3 \mathrm{~mm}$.

Así mismo, en cada paciente se practicaron secuencias ponderadas en SE T2 con un TR de $2420 \mathrm{msg}$, TE de $96 \mathrm{msg}$, FOV de 20 x $20 \mathrm{~cm}$, matriz de 256 x 224, en el plano axial de igual espesor de corte.

Las imágenes fueron reproducidas en películas $\mathrm{O}$ placas (Plus de tamaño 35 x $43 \mathrm{~cm}$ de 3M España, en un equipo automático Laser Imagen Plus 3M España (St Paul, EE.UU.).

Después de realizarse el diagnóstico radiológico por
$\mathrm{RM}$, todas las lesiones de las glándulas salivales fueron evaluadas por citopatología en primer lugar, tras la técnica de punción aspiración con aguja fina (PAAF) y posteriormente, por histopatología, tras su extirpación quirúrgica, excepto los casos de sialoadenitis.

Se realizó una estadística descriptiva simple de los hallazgos obtenidos.

\section{RESULTADOS}

18 pacientes ancianos con presencia de una tumoración glandular salival fueron diagnosticados por RM. En 17 pacientes, la tumoración se localizaba en la glándula parótida, y en 1 paciente, en la glándula submaxilar. La localización glandular del tumor fue unilateral en el $100 \%$ de los pacientes (Tabla 1).

En el presente estudio, los tumores salivales benignos $(44,4 \%)$ por RM, muestran imágenes homogéneas, de márgenes bien delimitados y encapsuladas (Tabla 2). En relación al tejido glandular sano, el tumor benigno, en las secuencias SE ponderadas en T1, presenta imágenes con una intensidad de señal hipointensa (no brillante o gris) en el $87,5 \%$ de los

TABLA 2. HALLAZGOS POR RESONANCIA MAGNÉTICA EN LA PATOLOGÍA SALIVAL

\begin{tabular}{|c|c|c|c|c|c|c|}
\hline Paciente & Tamaño $\mathrm{cm}$ & Márgenes & Adenopatías & Imagen & Señal $T 1$ & Señal T2 \\
\hline 1 & 3 & Bien delimitado & No & Homogénea & Hipointensa & Hiperintensa \\
\hline 2 & - & - & - & - & - & - \\
\hline 3 & 1,5 & Mal delimitado & No & Heterogénea & Hipointensa & Hiperintensa \\
\hline 4 & 2,5 & Bien delimitado & No & Homogénea & Hipointensa & Hiperintensa \\
\hline 5 & 3,5 & Mal delimitado & Sí & Homogénea & Hipointensa & Hipointensa \\
\hline 6 & - & Bien delimitado & No & Heterogénea & Hipointensa & Hiperintensa \\
\hline 7 & 3,5 & Bien delimitado & No & Homogénea & Hiperintensa & Hiperintensa \\
\hline 8 & 4 & Mal delimitado & Sí & Heterogénea & Hipointensa & Hipointensa \\
\hline 9 & 3 & Bien delimitado & No & Homogénea & Hipointensa & Hiperintensa \\
\hline 10 & 2,5 & Bien delimitado & No & Homogénea & Hipointensa & Hiperintensa \\
\hline 11 & - & Mal delimitado & No & Heterogénea & Hipointensa & Hiperintensa \\
\hline 12 & 3 & Bien delimitado & No & Homogénea & Hipointensa & Hiperintensa \\
\hline 13 & 2,5 & Mal delimitado & Sí & Homogénea & Hipointensa & Hiperintensa \\
\hline 14 & - & - & - & - & - & - \\
\hline 15 & 2 & Mal delimitado & Sí & Homogénea & Hipointensa & Hipointensa \\
\hline 16 & - & Mal delimitado & No & Heterogénea & Hipointensa & Hiperintensa \\
\hline 17 & 3,5 & Mal delimitado & Sí & Heterogénea & Hipointensa & Hipointensa \\
\hline 18 & 3 & Bien delimitado & No & Homogénea & Hipointensa & Hiperintensa \\
\hline
\end{tabular}



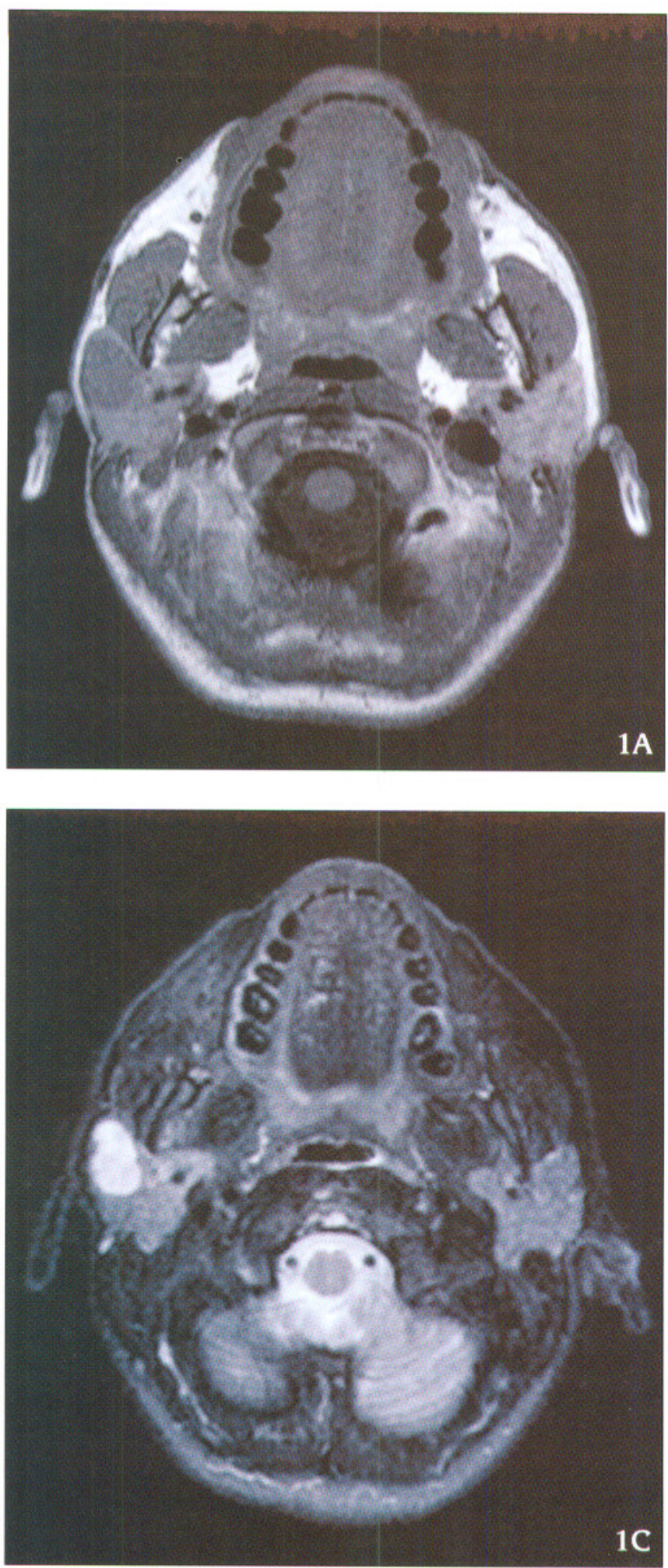

Figura 1. Imagen por resonancia magnética de tumor glandular salival benigno (adenoma pleomorfo de parótida izquierda). A) Secuencia ponderada T1 plano axial. B) Secuencia ponderada T1 plano coronal. C) Secuencia ponderada T2 plano axial. Caso 10.
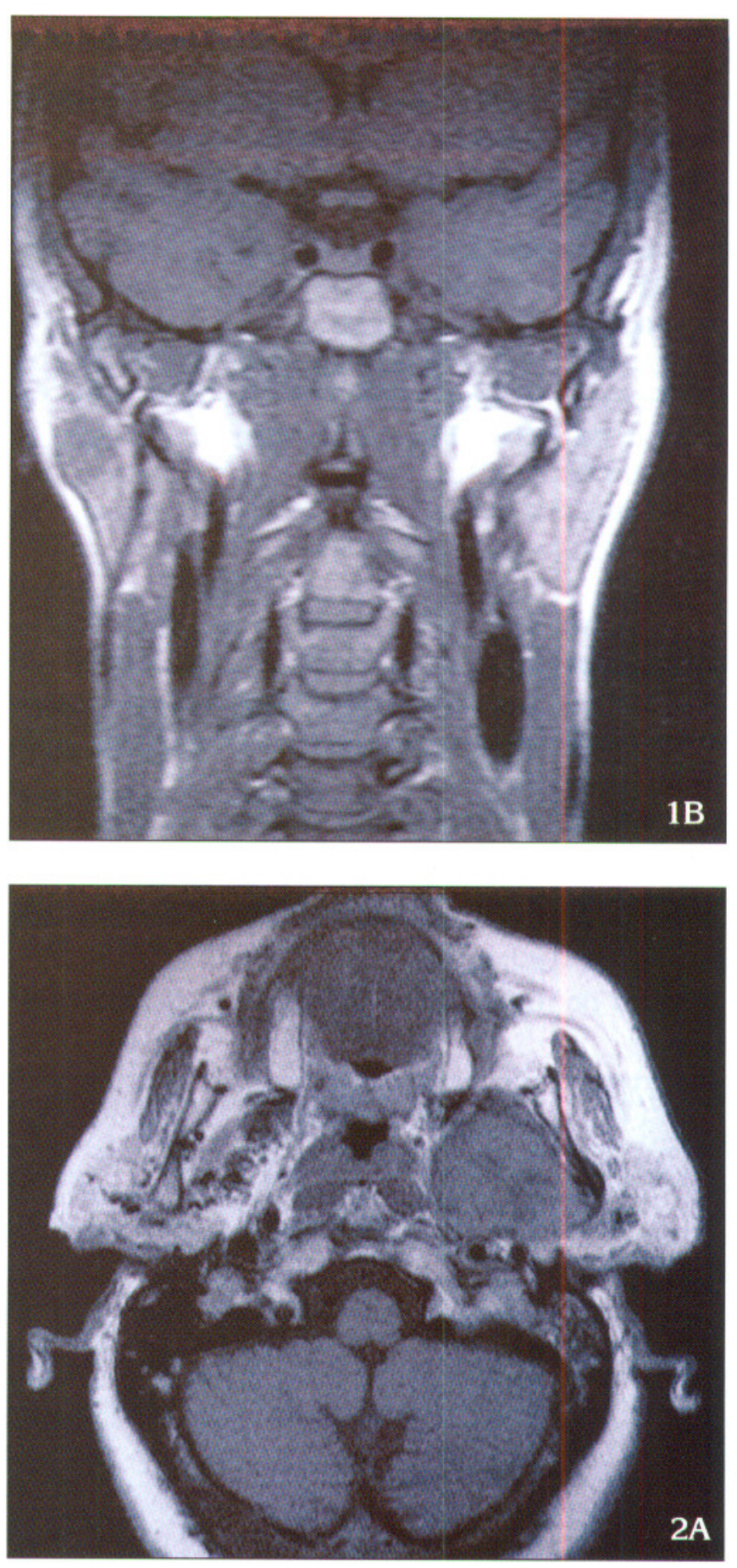

casos estudiados (excepto en el lipoma que es hiperintensa, Caso 7); mientras que en las secuencias SE ponderadas T2, la intensidad de señal es hiperintensa (brillante o blanca) en el 100\% (Figura 1).

La RM en los tumores salivales malignos $(27,7 \%)$ muestra imágenes heterogéneas, de márgenes mal 

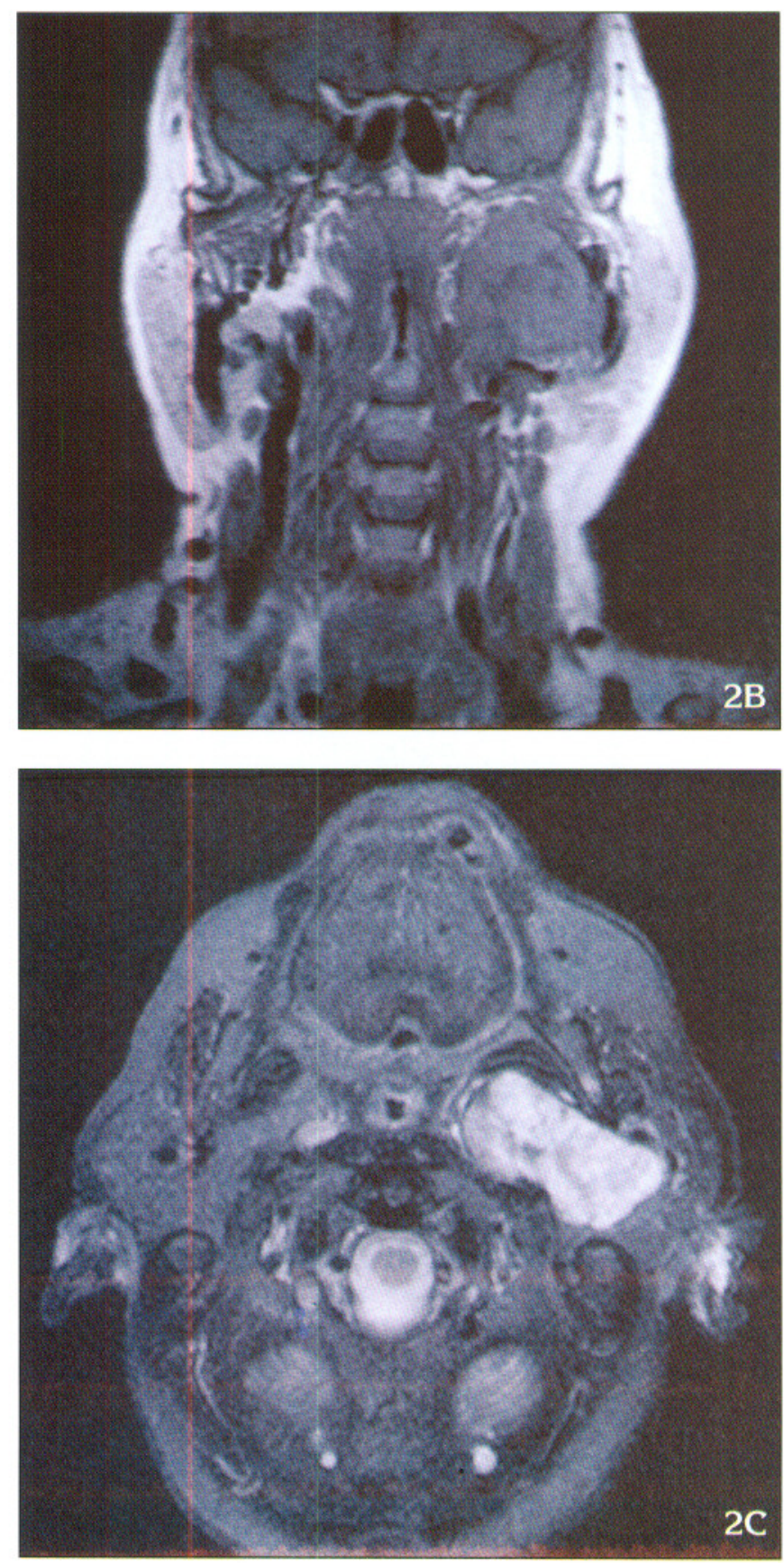

Figura 2. Imagen por resonancia magnética de tumor glandular salival maligno (carcinoma mucoepidermoide de parótida derecha). A) Secuencia ponderada T1 plano axial. B) Secuencia ponderada T1 plano coronal. C) Secuencia ponderada T2 plano axial. Caso 5.

delimitados, no encapsulados (Tabla 2). En relación al tejido glandular salival sano, los tumores malignos presentan imágenes con una intensidad de señal hipointensa en ambas secuencias SE ponderadas T1 y T2 (excepto en el carcinoma anaplásico de la presente serie, Caso 13). La presencia de adenopatías,
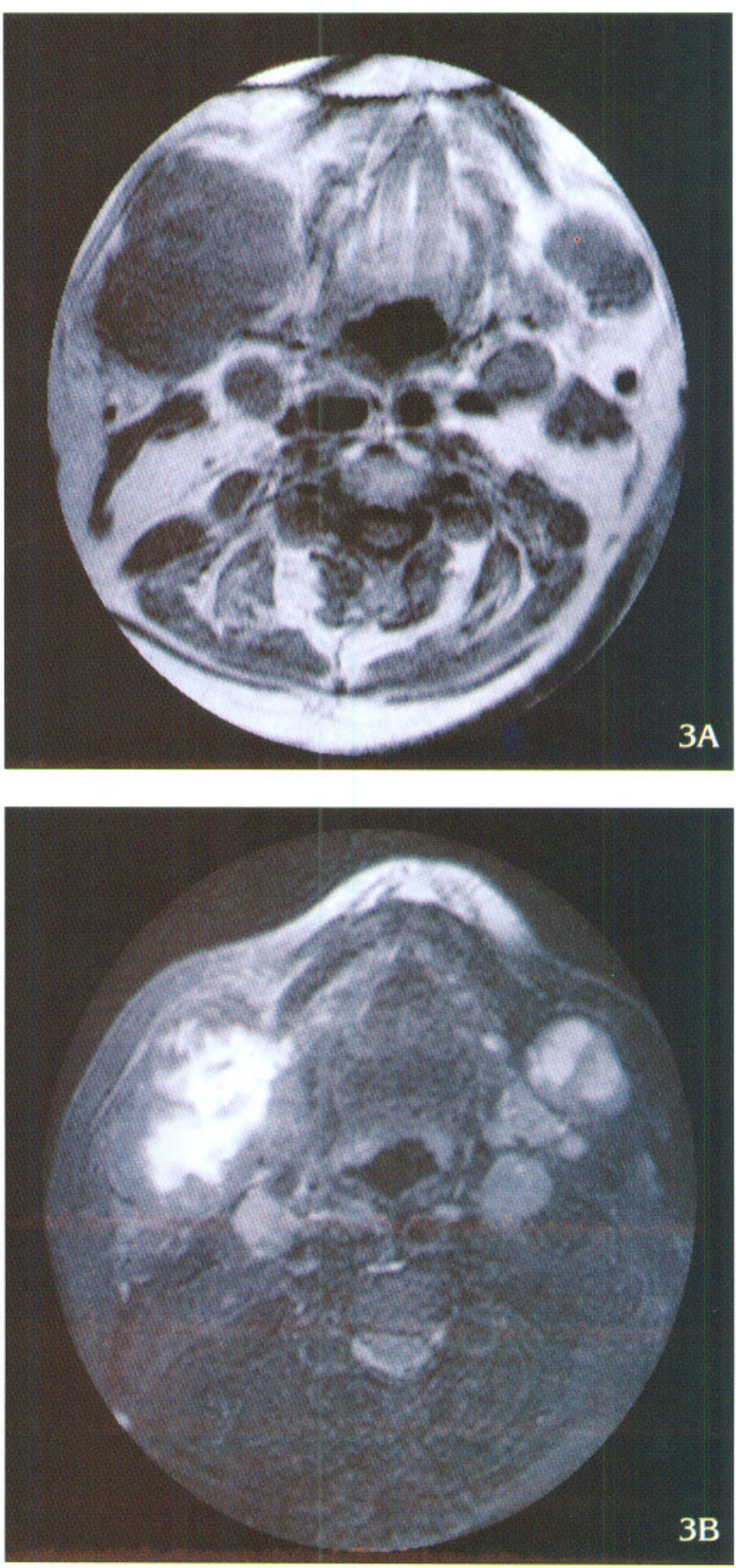

Figura 3. Imagen por resonancia magnética de sialoadenitis submaxilar izquierda. A) Secuencia ponderada T1 plano axial. B) Secuencia ponderada T2 plano axial. Caso 11.

fundamentalmente de localización cervical, fue un hallazgo en las imágenes por RM en el $100 \%$ de los pacientes con el diagnóstico de tumor salival maligno (Figura 2). 

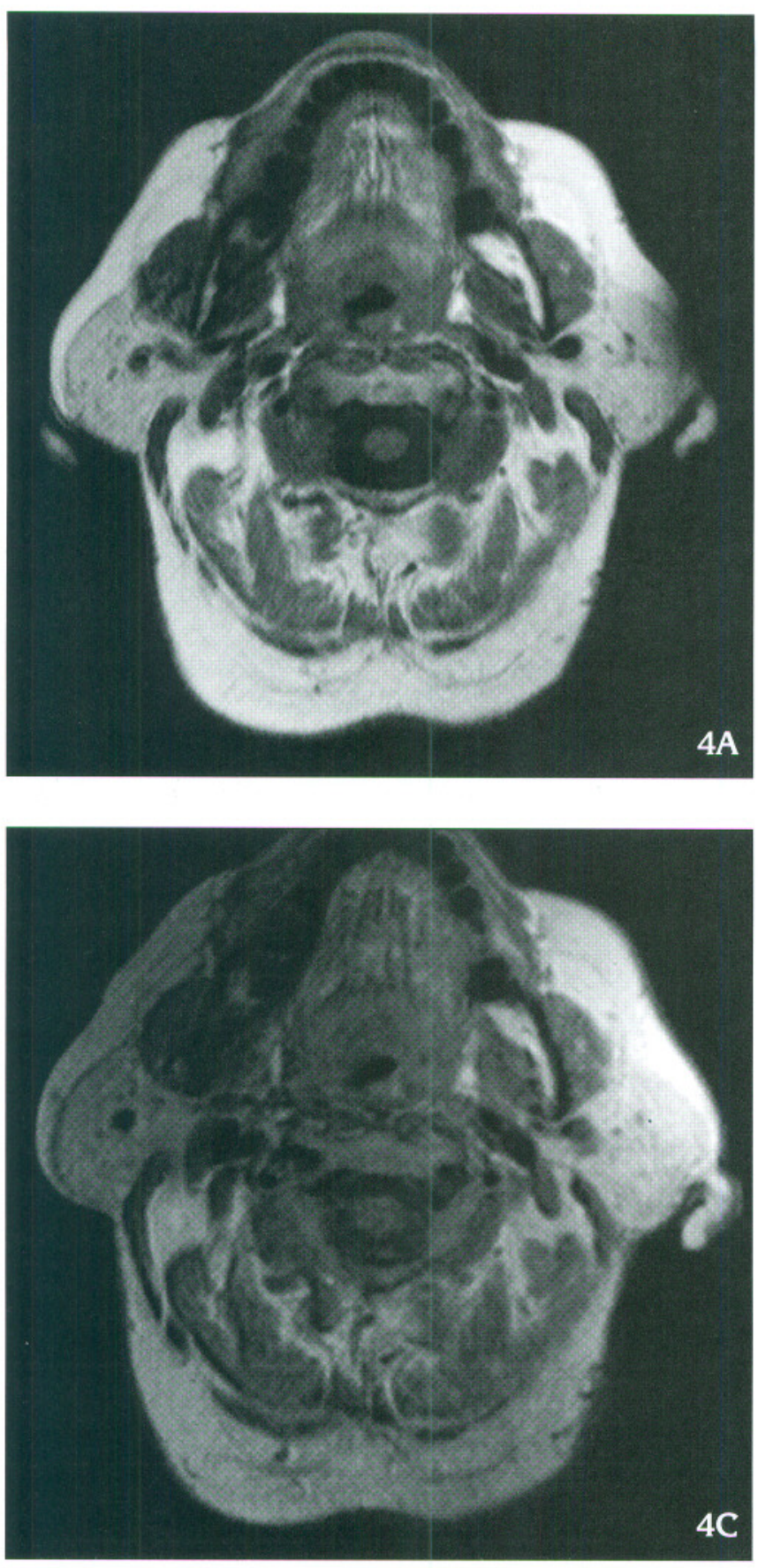

Figura 4. Imagen por resonancia magnética de síndrome de Sjögren. A) Secuencia ponderada T1 plano axial. B) Secuencia ponderada T1 plano coronal. C) Secuencia ponderada T2 plano axial. Caso 6.

La RM en la patología glandular salival inflamatoria $(11,1 \%)$, muestra un aumento del tamaño glandular con imágenes heterogéneas, de márgenes mal delimitados (Tabla 2). En relación al tejido glandular salival sano, los procesos inflamatorios presentan imágenes con una intensidad de señal hipointensa en la

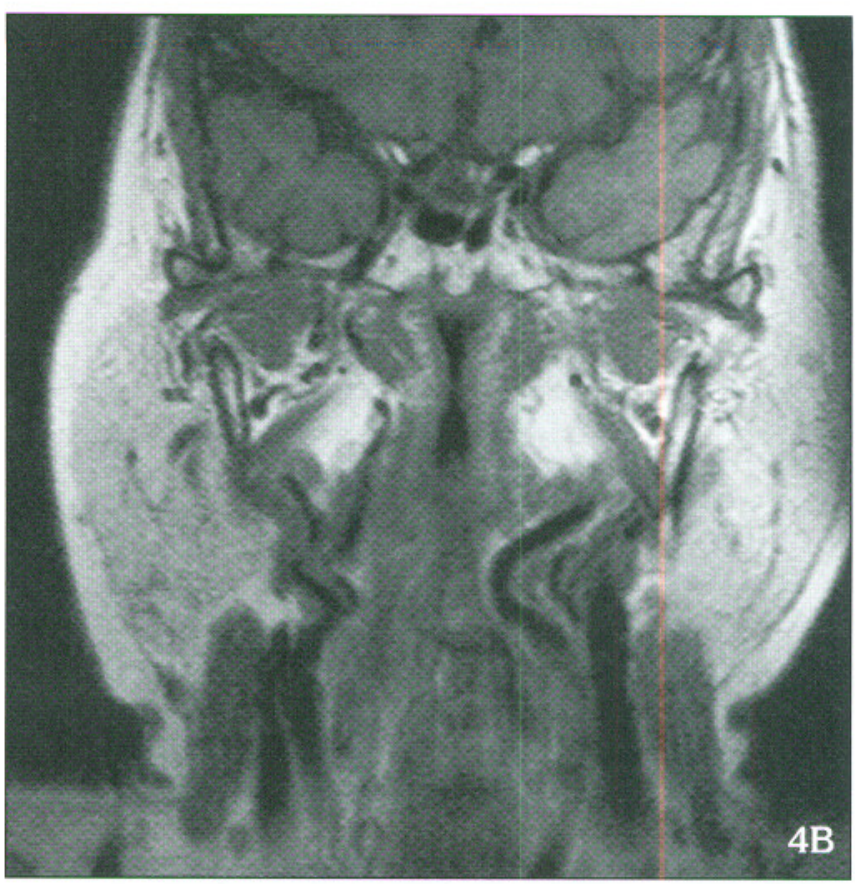

secuencia SE ponderada T1 e hiperintensa en la secuencia SE ponderada T2 (Figura 3).

La RM en las lesiones sospechosas de síndrome de Sjögren (5,5\%), muestra un aumento del tamaño glandular con imágenes heterogéneas, de márgenes bien delimitados (Tabla 2). En relación al tejido glandular salival sano, el síndrome de Sjögren presenta imágenes con una intensidad de señal hipointensa en la secuencia SE ponderada T1 e hiperintensa en la secuencia SE ponderada T2 (Figura 4).

\section{DISCUSIÓN}

El presente estudio proporciona una visión general de la utilización de la RM como medio de diagnóstico por la imagen en la patología de las glándulas salivales en el paciente anciano. En este sentido, en el presente trabajo se establecen los criterios de identificación por RM, de los procesos patológicos que afectan a las glándulas salivales en los adultos de edad avanzada.

Generalmente, la patología glandular salival entre los pacientes ancianos, es sospechada mediante la historia clínica y la exploración física, y ha sido confirmada en los últimos 20 años mediante métodos complementarios por la imagen (radiología simple, 
sialografía, ecografía, TC, isótopos radioactivos). Más recientemente, la RM se ha ido incorporando al estudio de la patología de las glándulas salivales (3). De hecho, la RM ofrece ventajas importantes con respecto a las otras pruebas diagnósticas por la imagen, como un mejor contraste entre las partes blandas orofaciales, la obtención de cortes multiplanares y la no utilización de radiaciones ionizantes (5).

\section{SÍNDROME DE SJÓGREN}

El síndrome de Sjögren constituye la enfermedad autoinmune más frecuente a nivel de las glándulas salivales. Aunque el diagnóstico fundamental se realiza mediante la biopsia de las glándulas salivales menores labiales, la sialografía orienta el diagnóstico. Las imágenes sialográficas del síndrome de Sjögren son suficientemente específicas y permiten su diferenciación al revelar colecciones puntiformes, globulares o cavitarias según la evolución del proceso autoinmunitario (3).

En el síndrome de Sjögren, la RM muestra, fundamentalmente, la existencia de una sialomegalia difusa (Figura 4). En la RM, los conductos intraglandulares y acinos dilatados son hipointensos en T1 e hiperintensos en T2. El componente linfocitario y el tejido colágeno son hipointensos en T1 y T2. Así mismo, una indicación precisa e importante de la RM en el síndrome de Sjögren puede ser la visualización de cambios en las imágenes glandulares salivales que se correspondan con el desarrollo de linfomas en estos pacientes en el curso de su evolución clínica (3).

La RM-sialografía constituye una nueva técnica que permite el estudio del sistema salival ductal de las glándulas salivales mayores en los pacientes con el síndrome de Sjögren sin necesidad de administrar contraste sialográfico, mostrando las alteraciones ductales y acinares progresivas con la evolución del proceso y que están correlacionadas con los resultados de la biopsia labial (6-7).

Además, se ha demostrado una correlación entre las imágenes por RM y las alteraciones clínicas y de laboratorio de los pacientes con Sjögren, lo que puede contribuir al diagnóstico del proceso sin necesidad de recurrir a la biopsia de las glándulas saliva- les menores. En este sentido, la biopsia glandular salival tiene limitaciones, porque pueden existir alteraciones por el envejecimiento en los pacientes mayores sanos, similares a las descritas en los pacientes con síndrome de Sjögren (8).

\section{SIALOADENITIS}

Clásicamente, la inflamación aguda de las glándulas salivales, especialmente la parótida, se ha diagnosticado por la historia clínica y la exploración física en el curso de brotes epidémicos en pacientes infantiles. La parotiditis aguda es rara en los pacientes mayores, sin embargo la submaxilitis puede suceder por la obstrucción del conducto de Wharton como consecuencia de una litiasis salival. La sialografía está contraindicada en la sialoadenitis aguda porque facilita la propagación de la infección hacia la profundidad de la glándula (9).

En cambio, la RM no presenta contraindicación en el estudio de la patología inflamatoria aguda, permitiendo demostrar el aumento del tamaño glandular (Figura 3), la extensión de la inflamación a los tejidos vecinos, la presencia de adenopatías inflamatorias, así como los cambios intraglandulares y la posibilidad de complicaciones (absceso) en la evolución clínica. Cuando existe sospecha de sialoadenitis por litiasis salival, puede ser recomendable la radiografía simple o la TC por mostrar una mayor resolución que la RM para la detección del cálculo (10).

\section{TUMORES BENIGNOS}

Es en el campo de la patología salival tumoral donde la RM adquiere un gran valor diagnóstico (3-5). En el presente estudio, se valoraron 8 pacientes ancianos con tumores benignos de las glándulas salivales. La identificación de la lesión tumoral benigna fue establecida en el $100 \%$ de los casos previamente al estudio histopatológico, incluyendo un caso de recidiva tumoral tras la eliminación quirúrgica de un adenoma pleomórfico sin la extirpación total de la glándula parótida afectada (Caso 3).

Las características clínicas del tumor salival benigno reflejan la existencia de un aumento de tamaño glan- 
dular localizado o generalizado, frecuentemente unilateral, no doloroso, de evolución lenta. La RM establece el diagnóstico de tumor benigno por la presencia de una masa de márgenes bien delimitados, encapsulada, que no infiltra los tejidos vecinos, sin la presencia de adenopatías metastásicas. Las características de señal ayudan a establecer el diagnóstico diferencial entre los tumores benignos. Así, la RM muestra una homogeneidad de la masa tumoral en ambas secuencias, hipointensa en T1 e hiperintensa en T2 (Figura 1), excepto en el lipoma que es hiperintenso en ambas secuencias (11-12).

\section{TUMORES MALIGNOS}

La RM es el método diagnóstico por la imagen de elección para el estudio de la patología tumoral maligna que afecta a las glándulas salivales (13). En el presente estudio, se evaluaron 7 pacientes mayores con sospecha de tumor salival maligno, de los cuales 2 correspondían a posibles recidivas tumorales tras la cirugía. Se identificaron todos los casos como tumores malignos, aunque la histopatología estableció el tipo específico de la lesión maligna. Así mismo, la RM demostró la ausencia de recidiva tumoral en los pacientes sospechosos de la misma (Casos 2 y 14).

Los tumores salivales malignos se caracterizan por una clínica de sialomegalia frecuentemente dolorosa y de rápida evolución. La RM establece el diagnóstico de lesión salival maligna por la existencia de una tumoración de márgenes irregulares e infiltrantes, no encapsulada, que puede comprometer el paquete vasculonervioso, posible invasión de los músculos masticatorios (Figura 2) y frecuente presencia de adenopatías metastásicas. Las características de señal ayudan a establecer el diagnóstico diferencial entre benignidad y malignidad (14-16). Así, la RM en los tumores malignos muestra una masa heterogénea, con una intensidad de señal hipointensa en ambas secuencias (Tablas 1 y 2).

La intensidad de señal de las imágenes por RM puede relacionarse con el grado de malignidad de los tumores salivales. Las lesiones tumorales malignas de bajo grado de agresividad (carcinoma mucoepidermoide de bajo grado) pueden presentar una hiperintensidad moderada en la secuencia T2, que se relaciona inver- samente con el grado de celularidad de la lesión, es decir, cuanto más intensidad de señal, menor celularidad y por lo tanto, menor agresividad (17-18).

La RM ha demostrado ser una técnica por la imagen superior a la TC en el diagnóstico de la patología salival tumoral, tanto en las lesiones benignas como malignas. La RM permite una mejor identificación de la masa tumoral, de sus relaciones intraglandulares con el paquete vasculonervioso, así como extraglandulares (extensión a base de cráneo y cuello) lo que ayuda a establecer una adecuada planificación en el tratamiento quirúrgico (18-20).

\section{CONCLUSIONES}

Aunque la historia clínica y la exploración física representan la base del diagnóstico de las lesiones glandulares salivales en el paciente anciano, las diferentes técnicas por la imagen ayudan a establecer el diagnóstico etiológico de esta diversa patología, que confirmará posteriormente el estudio histopatológico. En este sentido, la radiología simple, la ecografía, la sialografía y la TC contribuyen al conocimiento de los diversos procesos patológicos salivales. Sin embargo, en la actualidad, la RM ha demostrado ser un método muy eficaz, sobre todo en la evaluación de la patología salival tumoral, donde constituye el método de diagnóstico por la imagen de primera elección.

\section{BIBLIOGRAFÍA}

1. López JL, Birichinaga B, Alonso J. Tumores de glándulas salivales: estudio retrospectivo de 128 casos. Arch Odontoestomatol 1996; 12: 49-56.

2. Rapidis Ad, Keramidas T, Panagiotopoulos H, Andressakis D, Angelopoulos AP. Tumours of the head and neck in the elderly: analysis of 190 patients. J CranioMaxilloFac Surg 1998; 26: 153-8.

3. Som PM, Brandwein M. Salivary glands. En: Som PM, Curtin HD, eds. Head and neck imaging II. $3^{\mathrm{a}}$ ed. St. Louis, EE.UU.: Mosby, 1996: 823-914.

4. Weissman JL. Imaging of the salivary glands. Semin Ultrasound CT MR 1995; 16: 546-68. 
5. Paz J, Velasco E, Bullón P. La resonancia magnética en el diagnóstico por imagen de la patología glandular salival. Arch Odontoestomatol 1997; 13: 217-24.

6. Jungehulsing $M$, Fischbach $\mathrm{R}$, Schroder $U$, Kugel H, Damm M, Eckel HE. Magnetic resonance sialography. Otolaryngol Head Neck Surg 1999; 12: 488-94.

7. Tonami H, Ogawa Y, Matoba M et al. MR sialography in patients with Sjögren syndrome. Am J Neuroradiol 1998; 19: 1199-203.

8. Izumi $M$, Eguchi K, Ohki M, et al. MR imaging of the parotid gland in Sjögren syndrome: A proposal for new diagnostic criteria. Am J Radiol 1996; 166: 1483-7.

9. Paz J, Velasco E, Bullón P. La resonancia magnética en el diagnóstico de la patología inflamatoria parotídea. An Odontoestomatol 1996; 3: 154-7.

10. Kaneda T, Minami M, Ozawa $\mathrm{K}$ et al. MR of the submandibular gland: normal and pathologic status. Am J Neuroradiol 1996; 17: 1575-81.

11. Paz J, Velasco E, Manso F, Bullón P. La imagen por resonancia magnética en el diagnóstico de los adenomas pleomorfos de parótida. Medicina Oral 1997; 2: 271-82.

12. Paz J, Velasco E, Martinez-Sahuquillo A, Bullón P. La resonancia magnética en el diagnóstico diferencial por la imagen de los tumores salivales benignos. Odontoestomatol Pract Clinic 2000; 3: 76-81.
13. Paz J, Velasco E, Manso F, Martinez-Sahuquillo A, Bullón P. El diagnóstico por resonancia magnética de los tumores malignos de las glándulas salivales. Odontoestomatol Pract Clinic 1998; 1: 25-33.

14. Kaneda T, Minami $M$, Ozawa $\mathrm{K}$ et al. Imaging tumors of the minor salivary glands. Oral Surg Oral Med Oral Pathol 1994;77:385-90.

15. Silvers AR, Som PM, Brandwein M. Epithelialmyoepithelial carcinoma of the parotid gland. Am J Neuroradiol 1996; 17: 560-2.

16. Sakai O, Nakashima N, Takata Y, Furuse $M$. Acinic cell carcinoma of the parotid gland: CT and MRI. Neuroradiology 1996; 38: 675-9.

17. Sigal R, Monnet O, de Baere T et al. Adenoid cystic carcinoma of the head and neck: evaluation with MR imaging and clinical-pathologic correlation in 27 patients. Radiology 1992; 184: 95-101.

18. Joe VQ, Westesson PL. Tumors of the parotid gland: MR imaging characteristics of various histologic types. Am J Radiol 1994; 163: 433-8.

19. Dailiana T, Chakeres D, Schmalbrock P, Williams P, Aletras A. High-resolution MR of the intraparotid facial nerve and parotid duct. Am J Neuroradiol 1997; 18: 165-72.

20. Ariyoshi Y, Shimahara M. Determining whether a parotid tumor is in the superficial or deep lobe using magnetic resonance imaging. J Oral Maxillofac Surg 1998; 56: 23-6. 